UNIVERSIDADE ESTADUAL DE FEIRA DE SANTANA

Autorizada pelo Decreto Federal no 77.496 de 27/04/76
Recredenciamento pelo Decreto n ${ }^{\circ} 17.228$ de 25/11/2016

PPPG PRÓ-REITORIA DE PESQUISA E PÓS-GRADUAÇão

XXIII SEMINÁRIO DE INICIAÇÃO CIENTÍFICA DA UEFS

SEMANA NACIONAL DE CIENTÍFICA E TECNOLÓGICA - 2019

\title{
IMPACTOS DA IMPLANTAÇÃO DE INDÚSTRIAS NO DISTRITO DE MARIA QUITÉRIA
}

\author{
$\underline{\text { Jacqueline de Jesus Bastos }}{ }^{1}$; Janio Santos²; \\ 1. Bolsista PROBIC/UEFS, Graduanda em Licenciatura de Geografia, Universidade Estadual de Feira de Santana, e- \\ mail: jack_fsabastos@hotmail.com \\ 2. Jânio Laurentino de Jesus Santos, Departamento de Ciências Humanas e Filosofia, Universidade Estadual de Feira \\ de Santana, e-mail: Janiosantos@yahoo.com.br
}

PALAVRAS-CHAVE: Indústria, Vilas, socioeconômico.

\section{INTRODUÇÃO}

O Brasil ainda é considerado um país em desenvolvimento, face ao processo de industrialização tardia, em relação ao que ocorreu nos países centrais. As indústrias no Brasil começaram a desenvolver a partir das mudanças estruturais na economia, política e sociedade, no fim do século XIX. Um dos fatores que ajudaram no processo de industrialização no Brasil foi a crise na exportação de café, a qual gerou mudanças nos focos dos investimentos estatais para as indústrias (SCANTIMBURGO, 1980).

No caso do município de Feira de Santana/BA, nota-se que esse possui um Centro Industrial que é relevante para a cidade, como também para o Estado da Bahia. No Centro Industrial de Subaé (CIS), conhecido como o "Bairro Industrial", estão instaladas indústrias que atuam em diversos ramos na economia: indústrias de alimentos, bebidas, materiais elétricos, papel/papelão e embalagens, transportes, farmacêuticos, dentre outros. A concentração dessas indústrias ocorre, em sua maioria, na parte sul da cidade. Todavia, ao decorrer dos anos, percebe-se um interesse em expandir essa industrialização para o norte de Feira de Santana, local que foi pouco explorado em pesquisas, até então.

Com o crescimento da industrialização no Brasil, não se pode deixar de notar a expansão da atividade industrial existente em locais delimitados como perímetro rural, sendo exemplo dessa expansão as implantações das indústrias B.N Mascarenhas, Incomprel e das fábricas Avanço Distribuidora e Globalpark na BR 116 norte, entre a Universidade Estadual de Feira de Santana (UEFS) e o Distrito de Maria Quitéria, então área rural.

O foco principal deste artigo é analisar, com base na formação da Vila e suas modificações, as implicações da instalação de indústrias/fábricas no entorno do Distrito de Maria Quitéria, em Feira de Santana/BA, e avaliar os possíveis impactos socioeconômicos desenvolvidos no espaço da comunidade, após essas implantações. 


\section{MATERIAL E MÉTODOS OU METODOLOGIA}

Sobre os levantamentos bibliográficos, essa pesquisa trabalhou com os conceitos de industrialização, vilas, relação cidade-campo, sobremodo, com base em autores Sposito (2003), Lessa (2007), Freitas (1998), Santos (1999), dentre outros.

$\mathrm{Na}$ visita de campo ao distrito Maria Quitéria foram aplicados 50 questionários aos moradores, com critério de avaliação sobre a relação deles com o emprego existente antes e após as implantações das indústrias. Foram aplicadas duas entrevistas com moradores antigos sobre o processo histórico de formação do Distrito de Maria Quitéria. Também, foi aplicada uma entrevista com a Professora $\operatorname{Dr}^{\mathrm{a}}$ Nacelice Freitas, com o intuito de saber informações sobre as características dessas indústrias/fábricas.

No campo foram coletados dados para fazer um mapa de uso e ocupação do solo na sede do distrito de Maria Quitéria.

\section{RESULTADOS E/OU DISCUSSÃO}

Maria Quitéria é um distrito pertencente à zona rural do município de Feira de Santana, situado no Noroeste (mapa 2), com 13.903 habitantes, sendo 1.826 na sua sede, sendo o maior distrito, em população, segundo o IBGE (2010), além de ser um dos percussores da formação territorial de Feira de Santana. No passado, o distrito possuía outra nomenclatura, que até hoje é usada por muitos feirenses, que é São José das Itapororocas, na época, ainda pertencente ao município de Cachoeira.

Mapa 1: Localização do distrito de Maria Quitéria em Feira de Santana.
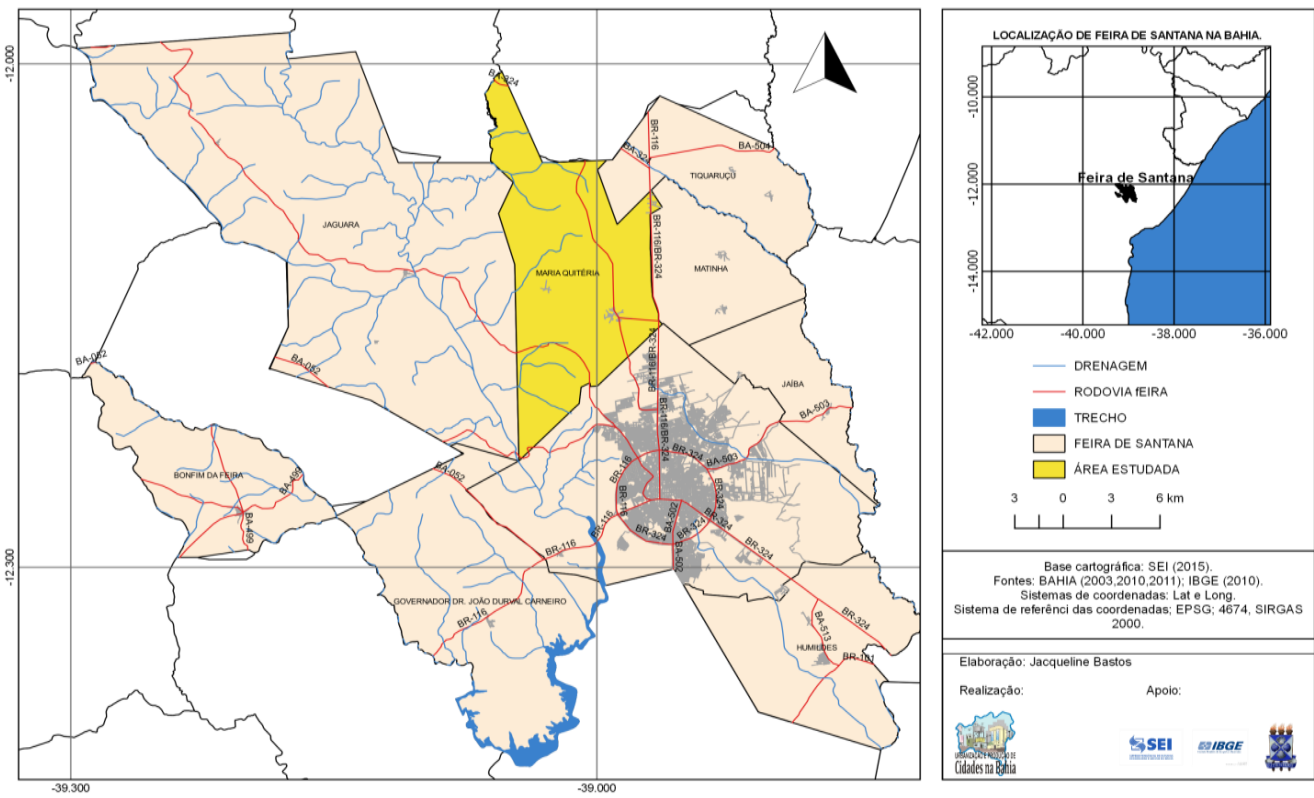

A chegada das indústrias/fábricas no entorno do distrito de Maria Quitéria foi bem rápida. Segundo os moradores, inicialmente, começaram a instalar vários galpões na BR 116 norte e depois de mais ou menos 1 ano entrou em funcionamento. Essas implantações ocorreram de forma verticalizada, sem nenhuma comunicação com a comunidade local.

Segundo os moradores ${ }^{1}$ essas atividades serão bem mais intensas no decorrer dos próximos anos, pois o discurso é que na área será construído um novo polo industrial e

\footnotetext{
${ }^{1}$ Questionário aplicado no distrito de Maria Quitéria, [jan. 2019]. Aplicadora: Jacqueline Bastos.
} 
as comunidades no seu entorno, a sede do distrito de Maria Quitéria e bairro Novo Horizonte, iriam se unir, tornando-os apenas um bairro, denominado com o mesmo nome do polo, Centro Industrial Norte (CIN). Apesar da comunidade informar dessa notícia, não foram encontrados documentos, nem houve nenhuma declaração oficial da Prefeitura de Feira de Santana.

A relação da atividade industrial com os moradores é bem fraca, pois quase não há conexões entre ambos, visto que $82 \%$ das residências entrevistadas não possuem nenhum morador que tenha tido contato direto com as indústrias, em relação a emprego. Todavia, mesmo que não possuam relação direta, 58\% desses moradores procuraram emprego nas indústrias/fábricas, ainda que não possuíram retorno. Isso mostra que o interesse na implantação de estabelecimentos como esses não é empregar os moradores locais, mas sim usar o local apenas como fonte de produção capitalista.

Sendo assim, nota-se que o interesse do capital produtivo não é empregar os moradores de Maria Quitéria, o fato de ter se instalado nesse local não significa que a comunidade local será beneficiada. As indústrias querem gerar cada vez mais capital, e estar localizado no seu entorno não necessariamente irá gerar um desenvolvimento para o distrito.

As indústrias não trouxeram nenhum problema para o distrito, mas após sua instalação, o local teve uma maior visibilidade atraindo o setor imobiliário, com divisões de loteamentos para construção de 3 condomínios residenciais e construção de uma galeria com diversos ramos comerciais.

Como sempre, as indústrias levam consigo consequentemente instituições de produção do capital, o que não necessariamente significa que os moradores serão beneficiados com essas chegadas nas comunidades, em entrevista com uma moradora, ela relatou que não houve aumento na empregabilidade das pessoas que residem no distrito, "Não vi muita mudança, não houve mais empregos para os moradores, nem qualquer outro benefício para nós.".

O mapa 2 retrata como é o uso e ocupação do solo na sede do distrito de Maria Quitéria, sendo de diversos setores, como saúde, educação, comercial, jurídico, religioso, segurança e lazer.

Os grandes destaques em relação a estabelecimentos de ocupação do solo são as mercearias e colégios, sendo eles públicos e privados, espalhados ao longo de todo a sede. $\mathrm{O}$ distrito possui alguns estabelecimentos em destaque, que segundo os moradores não é comum na zona rural, e seriam privilegiados por isso, como a biblioteca pública, cartório, correios e policlínica.

Mapa 2: Uso e ocupação do setor terciário na sede do distrito de Maria Quitéria.

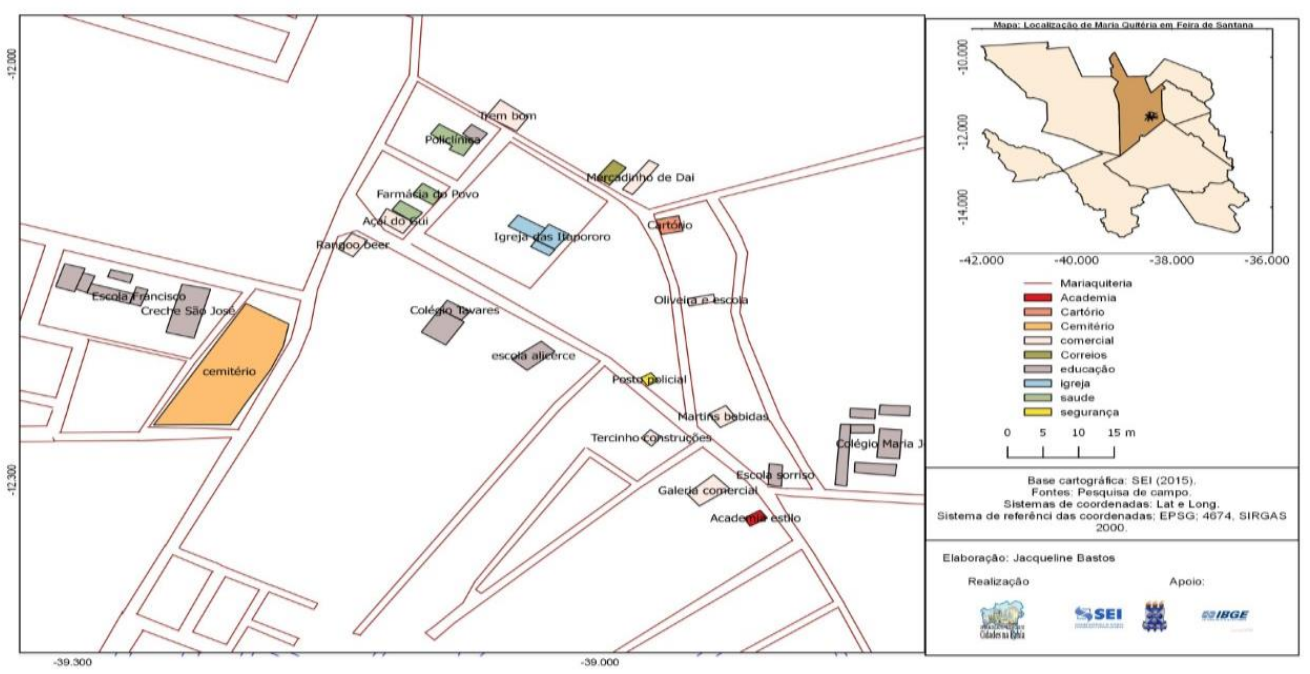




\section{CONSIDERAÇÕES FINAIS}

Com base nos levantamentos bibliográficos e nos dados obtidos através da aplicação de questionários e entrevistas realizados no trabalho de campo, verificou-se que com a chegada das indústrias/fábricas B.N Mascarenhas, Incomprel e das fábricas Avanço Distribuidora e Globalpark na BR 116 norte, trouxeram como consequência uma certa valorização e mudança no uso e ocupação do solo do distrito de Maria Quitéria, trazendo investimentos imobiliários e comerciais, tornando a vila cada vez mais urbanizada.

Em consequência da duplicação da BR 116 Norte, está valorizando mais ainda o solo no entorno das indústrias/fábricas, já que elas se localizam exatamente nesse local, trazendo mais investimentos de interesses industriais, surgindo um segundo Centro industrial de potência para o município de Feira de Santana. Dessa maneira, a implantação de um novo polo industrial será de suma importância para o processo de desenvolvimento socioeconômico tanto de Feira de Santana quando do distrito de Maria Quitéria, compreendendo que as indústrias/fábricas não possuem relação direta com a Vila.

Em relação aos moradores da Vila, é vidente que eles não estão sendo beneficiados economicamente em relação a chegada das indústrias/fábricas no seu entorno. Através do campo, verificou-se que a taxa de desemprego não diminuiu com essas implantações, mesmo os moradores procurando emprego nesses locais, não obtiveram retorno. O que nos faz refletir como a instalação de meios de produção capitalista não emprega os moradores que residem nesse local, mostrando, então, que o interesse desses empresários não são de favorecer as pessoas que estão ali, mas sim explorar o solo local.

\section{REFERÊNCIAS}

FREITAS, Nacelice Barbosa. Urbanização em Feira de Santana: Influência da industrialização 1970-1996. 180f. Dissertação (Mestrado em Arquitetura e Urbanismo) - UFBA, Salvador, 1999.

IBGE- INSTITUTO BRASILEIRO DE GEOGRAFIA E ESTATISTICA. Censo Demográfico 2010 - Feira de Sanatana. 2018. Disponível em: <https://cidades.ibge.gov.br/brasil/ba/feira-desantana/panorama>. Acesso em: 20 jan. 2019.

LESSA, Carlos. Política industrial e industrialização, Instituto de Economia da UFRJ, 2007. Disponível em: http://www.ie.ufrj.br/aparte/pdfs/lessa090507.pdf. Acesso em 20 de Out. 2018.

SANTOS, Telma Maria Souza dos. Territorialidade da Indústria de Alimentos Parmalat em Feira de Santana- Bahia. 190f. Dissertação (Mestrado em Geografia) -, UFBA, Salvador, 1999.

SCANTIMBURGO, João de. O café e o desenvolvimento do Brasil. Edições Melhoramentos, 224p. São Paulo, 1980.

SPOSITO, Maria Encarnação Beltrão. Capitalismo e Urbanização. 14. ed. São Paulo: Contexto, 2004. 